\title{
Contact mechanic issue in non-typical connections in hybrid timber structures
}

\author{
Arkadiusz Leśko ${ }^{1, *}$ \\ ${ }^{1}$ Warsaw University of Technology, Faculty of Civil Engineering, Division of Wood Structures, \\ Al. Armii Ludowej 16, Warsaw 00-637, Poland
}

\begin{abstract}
The paper relates to the issue of the contact mechanics in the innovative connections in hybrid timber structures. On the basis of the literature examples of the non-typical connections where the contact mechanic have to be investigated were discussed. In the paper are shown modern timber composites where connections are not systemized. Issue of the contact mechanic in finite element method related to the connections of the hybrid timber structures were elaborated. Spatial model of the "beam to beam" connection, based on the glued-in rods and advanced contact relations was shown. The necessity of the usage of advanced contact models was discussed and factors which affect the assumptions where presented.
\end{abstract}

\section{Introduction}

Connection in hybrid timber structures is an assembly of hybrid components, with usage of connectors and carpentry works to ensure mutual cooperation of the connected elements. It is the most responsive place in the structure of the object which has apart weakness inducted during montage and natural notches. Non-typical (experimental) connections are considered to be unique if they have at least one property listed below:

- compatibility with the atypical spatial positioning of the merged elements,

- compatibility with the atypical cross sections of joined elements,

- uniqueness of the solution is not subjected to the systemization,

- anility to transfer atypical load configuration,

- ability to carry loads under unusual service conditions.

Hybrid connections as the most loaded places in the constructions should be treated with distinctive precaution on each step of the creation of the structure. Created or designed connections ought to checked both: laboratory and in-situ tests. Examples of the hybrid connections are shown below.

*Corresponding author: a.lesko@il.pw.edu.pl 
a)

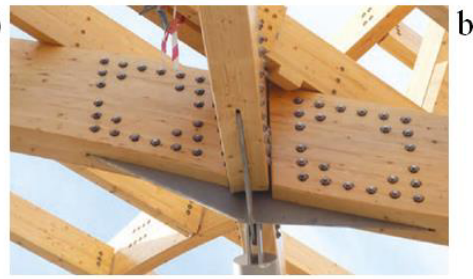

b)

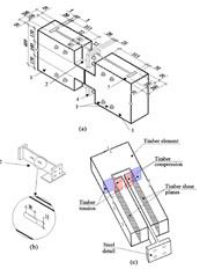

Fig. 1. Non-typical connections of timber structures.

(a) Join of the LVL structure [1]; (b) Screws connection without plates [2];

Connections shown above, based on non-typical structural design, allow for the merging specifically shaped elements with usage of "third" materials. However the internal structure of connected materials is constantly evolving what generate the need of creation new types of the joints based on sophisticated solutions and innovative materials. In particular, the development of the atypical architectural forms and the willing to create multistoreyed buildings in timber-composite technology, accelerates the evolution of hybrid materials.

a)

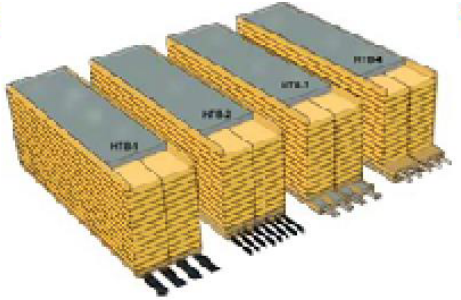

b)

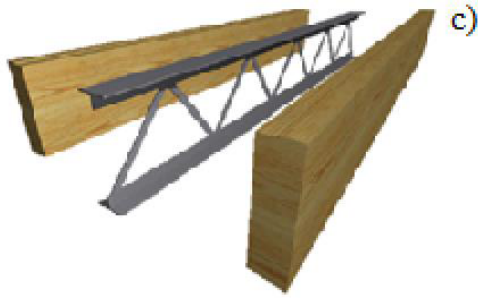

c)

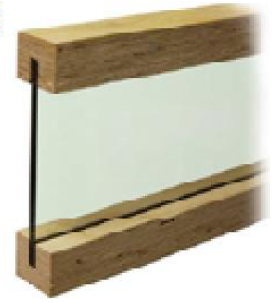

Fig. 2. Bar type composite elements (a) LVL based multi-composites [4];

(b) Hybrid beam Steel-LVL [5]; c) Innovative timber-glass beam composite [6];

Analysis of the connections of materials presented above requires the use of advanced scientific calculation methods and prioritization of the investigated phenomena. Contact mechanic is missed often enough and is replaced by "rigid conjunction" what is not always proper assumption. The issue of contact mechanics in term of timber structures connections is not systemized. Figure 3 depict unusual structural nodes what represents the complexity of the problem. Fig. 3 a) presents a geometrically complicated connection that does not require analysis of contact mechanic. Fig. $3 \mathrm{~b}$ ) presents a geometrically simple connection that require analysis of contact mechanic.

a)

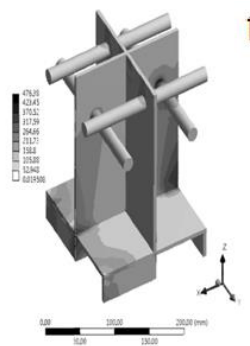

b)

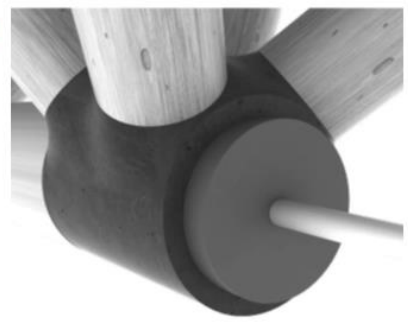

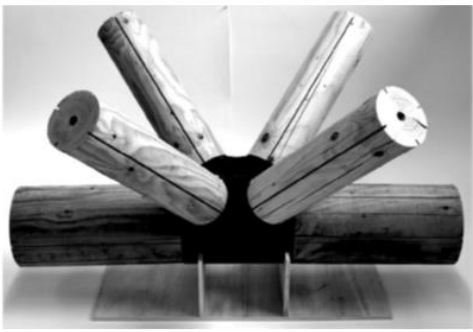

Fig. 3. a) geometrically complicated column base with stiffening connectors [7];

b) connection based on friction forces [8]; 


\section{Necessity of advanced contact models usage}

Contact mechanic in modern, hybrid timber structures is an essential issue. Due to the multitude of possible steps of load transfer, it is not possible to establish a universal path that would allow quick application of the basic assumptions to the numerical models.

- direct load transfer:

- friction,

- pressure,

- indirect load transfer:

- glues,

- mechanical fasteners (wooden, steel, composite...).

- $\quad$ direct and indirect load transfer (depending on the step).

The most common case is the "c" variant - depending on the state of stress the load is transferred in a different way. By strictly following the assumptions it is not possible to accurately reproduce the work of the connection with usage of the finite element method. It is therefore necessary to use a number of simplifications.

Due to the development of sophisticated structures (in particular hybrid timber structures) it is indispensable to define "computational parameters" allowing to implement simplified dimensioning of folded structural elements. In addition the use of advanced contact models allows for analytical verification of experimental results such as:

- rigidity of the frame structures nodes $k_{\theta}$ [9]

- redistribution of a complex load system [10]

- delineation of material structure [11]

- fatigue degradation of materials [12]

- influence of temperature on fasteners behavior [13]

Application of new measurement methods [15], increasing the accuracy and precision of laboratory experiments [14] and necessity to reinforce existing structures also entails the development of analytical models.

a)

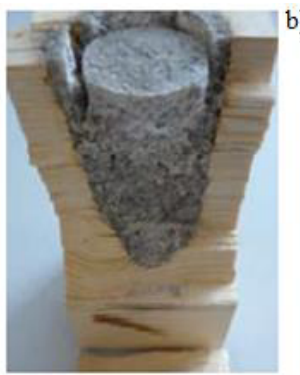

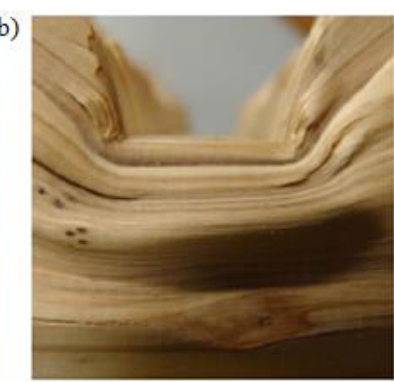

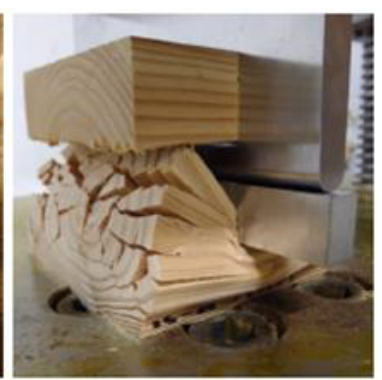

Fig. 4. Basic research based indirectly on the contact mechnics

(a) Junction based ona cement grout connector [17]; (b) Investigation of delamination [11]

\section{FEM issues related to the contact mechanics in the hybrid timber structures connections}

\subsection{Detection and discretization of contact zone}

The problem of frictionless contact for ideal bodies (smooth surface, lack of discontinuity, perfect adjust, etc.) comes down to analytical solution known as the "Hertz- SignoriniMoreau" problem [19,20,21]. Due to the complexity of hybrid connections in timber 
structures the analytical considerations are complicated. Wood (as a matrix) is a discrete fabric with numerous perturbations of a random nature. In addition typically hybrid connections are characterized by abrupt and high stiffness change in place of unmediated contact. Referring to the above it can be said that it is optimal to conduct detection analysis in hybrid timber structures by means of approximate methods - such as FEM.

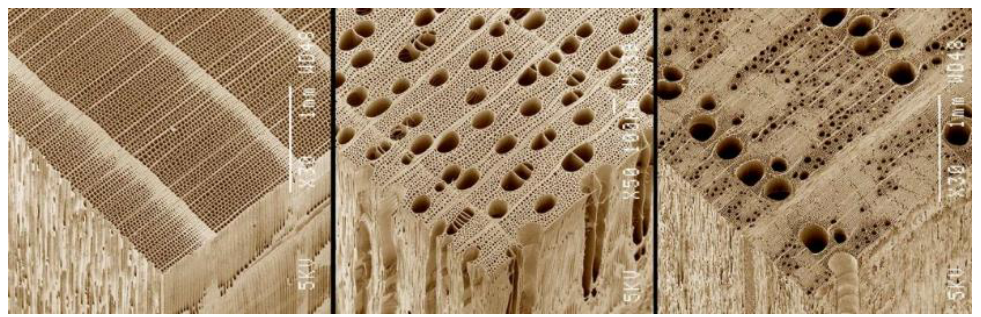

Fig. 5. Microscopic structure of different types of wood forcing the use of simplifications. [16]

\subsection{Contact discretization}

Discretization od the contact model is responsible for the proper propagation of stress between the combined materials. Publications such as $[22,23,24]$ deal with the discretization of the continuum wherewith most of the analytical considerations referring to solutions with usage of FEM.
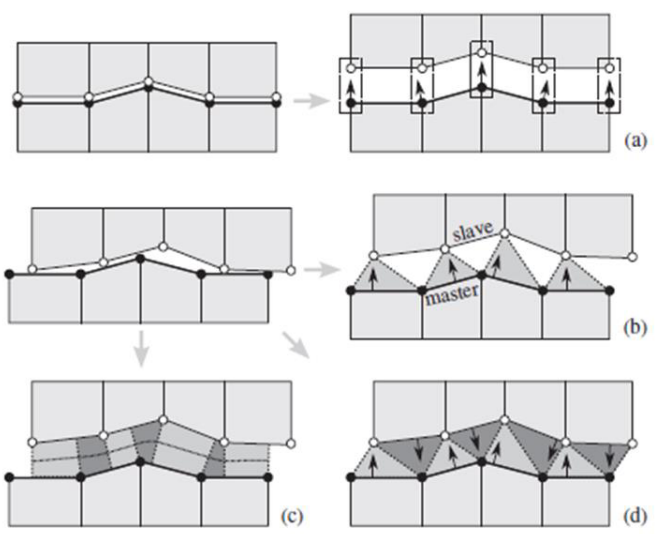

Fig. 6. Basic detection methods (related to discretization), method

(a) for small displacement, methods (b,c, d) for large displacement [19] (a)"NTN" - node to node; (b)"NTS" - nodet to segment; c)"STS" - segment to segment of ,contact domain method" type; d)"STS" - segment to segment of ,mortar method” type;

The methods above have their limitations [21] all the more they are the most popular methods and still being developed. There are also other methods like "ALL to ALL" type or mixed techniques, but they do not have any ready-made formulas or modules in computational programs.

Use of these methods is strongly correlated with the geometry of the tested structural elements, methods of discretization of the contact and expected results. Depending on the combination of connected materials (wood, steel, glass, concrete, composite, bitumen, etc.) it is necessary to observe the results, adjust the parameters calculation parameters and methods used to detect the contact. 


\subsection{Issue of contact in FEM - methods of solving}

Depending on the problem under investigation the method of solving the problem of contact should be selected. There are many relatively new methods such as: "Partitioning method", „SQP method", „Active set method" and many others. Due to simplicity and availability of software algorithms, despite their drawbacks, the most popular are:

- „Penalty Method" - it consist to select such a function of the "penalty” parameter (depending on whether or not the conditions of contact), which will not allow for interpenetration of connected elements. The advantages of this method are: easy physical interpretation of the phenomenon, lack of additional degrees of freedom and relatively good convergence. The disadvantages of penalty method are: the necessity of iterative matching penalty parameters and strong correlation between the results and the penalty function.

- „Lagrange Multiplier Method "- method taken from the optimization theory to obtain a convergent results at the expense of additional degrees of freedom.

These methods are used in one of the modules of "ABAQUS" program, such as „Contact pressure-overclosure relationship” or „Frictional behavior”. These ready-made algorithms can be used to create models of interactions in hybrid timber structures based on built-in relations. There are already first studies to investigate the possibility of using contact modules in timber joints [18] but they only concern the effects of normal loads (without the analysis of tangential stresses).
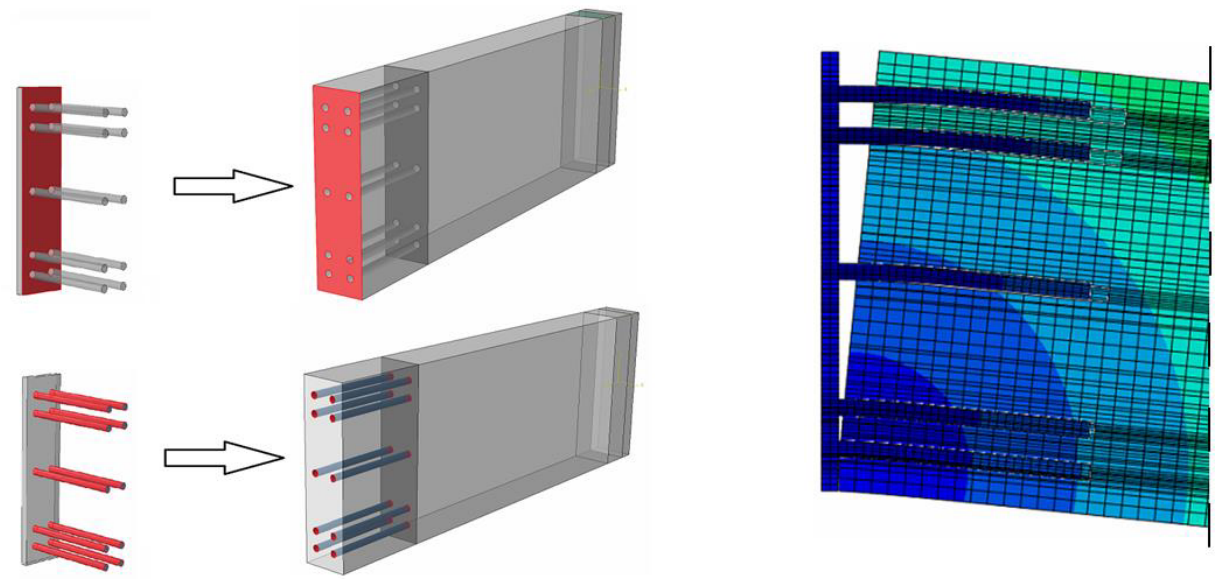

Fig. 7. Modeling attempt (maching of mechanical contact parameters) of the connection based on glued-in rods.[3]

\section{Parameters affecting the issue of contact.}

Apart from basic parameters being consequence of the implemented method of solving the contact problem, many factors affect both: the connection and the contact itself what should be considered in the investigation of the problem. These factors may have fundamental importance for the bearing capacity of the connected elements as a fasteners deadweight (or glue as a bonding medium) or the overall stability of the whole connection (SLS state). Two the most important parameters: the coefficient of friction and authentic (real) contact surface can be influenced by: duration of load, magnitude of load, degree of material effort, accuracy of adhesion of bonded surfaces, drop of roughness due to slipping, change in porosity due to the deformation, precision of the connection realization. 


\section{Conclusions}

Creation of new solutions and examination of existing hybrid timber structure coupling technologies is not possible without analysis of the stress propagation using the contact mechanics and FEM. There are simulation systems (ABQUS type) that allow to analyze modern conjunctions. It is necessary to conduct a series of experiments, both: simulation and laboratory tests to correlate the assumed coefficients and parameters in numerical calculations.

\section{References}

1. Glued laminated timber structures. Part 2: construction and connection details., 9 Structural Timber Engineering Bulletin (Structural Timber Association, 2014)

2. T. Gecys, A. Daniunas, T. K. Bader, L. Wagner, J. Eberhardsteiner, Engineering Structures 86, (2015)

3. A. Leśko, Proc. Eng. 153 (2016)

4. M. Jahreis, M. Kastner, W. Hadicke, K. Rautenstrauch, Materials and Joints in Timber Structures 9 (2014)

5. K. Tavoussi, W. Winter, T. Pixner, M. Kist, WCTE (2010)

6. M. Kozłowski, Badanie kompozytowych belek drewniano-szklanych (Monografie Wydziału Inżynierii Lądowej, Warszawa, 2015)

7. J. Humbert, S. Lee, J. Park, M. Park, Materials and Joints in Timber Structures 9, (2014)

8. K. Schober, T. Tannert, European Journal of Wood and Wood Products 74(3) (2016)

9. K. Malo, H. Stamatopoulos, World Conference on Timber Engineering e-book (2016)

10. T. Laggner, G. Flatscher, G. Schickhofer, World Conference on Timber Engineering ebook (2016)

11. A. Tabuchi, World Conference on Timber Engineering e-book (2016)

12. Z. Christian, S. Aicher, World Conference on Timber Engineering e-book (2016)

13. M. Alam, G. Hadjisophocleous, J. Erochko, World Conference on Timber Engineering e-book (2016)

14. F. Wolfthaler, M. Augustin, World Conference on Timber Engineering e-book (2016)

15. F. Giudiceandrea, E. Ursella, E. Vicario, World Conference on Timber Engineering ebook (2016)

16. http://botanik.pl/tag/drewno/

17. M. Jahreis, K. Rautenstrauch, World Conference on Timber Engineering e-book (2016)

18. B. Iraola, J. Cabrero, B. Gil, World Conference on Timber Engineering e-book (2016)

19. P. Wriggers, Computational contact mechanics, Second Edition (Springer, New York, 2006)

20. A. Rashid, Finite element modeling of contact problems, Linkoping Studies in Science and Technology, Dissertation No. 1736 (Linkoping, Sweden, 2016) 
21. V.A. Yastrebov, Numerical methods in contact mechanics (Wiley, Great Britain, 2013)

22. P. Wriggers, Nonlinear finite elements (Springer, New York, 2006)

23. J. T. Oden, Finite elements of nonlinear continua (McGraw-Hill, New York, 1972)

24. O. C. Zienkiewicz, T. L. Taylor, The finite element method-volume 2 (Oxford, United Kingdom, 2000) 